\title{
O som das escavadeiras
}

\section{The Sound of the Excavators}

\section{Simone Cortezão}

Cineasta, artista e doutora em Artes Visuais, Belo Horizonte, Minas Gerais / Brasil scortezao@gmail.com

Resumo: O texto narra um sonho que tive após três anos de filmagens em áreas de mineração e de resíduos industriais, denominadas aqui como zonas de ressaca. Ele adentra na discussão da ressaca e da percepção da realidade e dos acontecimentos, no ponto onde o som e a memória ultrapassam a imagem, trazendo a via do sonho como o pregnante e complexo fundo da memória, quando os fragmentos da invisibilidade da história atual despertam no campo frouxo do adormecer.

Palavras-chave: sonho; som; imagens oníricas; memória; ruínas; natureza.

Abstract: The text narrates a dream I had after three years of filming in mining and industrial waste areas, referred to here as undertow zones. It delves into the discussion of undertow and perception of reality and events at the point where sound and memory surpass the image, bringing the path of the dream as the meaningful and complex depth of memory when the fragments of the invisibility of present-day history awaken in the loose field of falling asleep.

Keywords: dream; sound; oneiric images; memory; ruins; nature.

Recebido em: 30 de agosto de 2017.

Aprovado em: 6 de fevereiro de 2018. 


\section{Introdução}

O texto a seguir deriva de uma pesquisa de doutorado sobre o desenho de forças do mundo, através do trânsito das matérias geológicas ou, como preferimos chamar de "recurso". Na busca em acionar, na dinâmica da própria escrita, entrelaçamentos entre natureza, ciência, memórias e ficção como formulação de um pensamento. Na tentativa de perceber pontos imperceptíveis, intoleráveis e violentos, de se pensar o movimento das forças remexidas e esgotadas da terra e de um futuro construído e desconstruído sobre bases materiais como o minério, o petróleo e a água, e de uma economia abstrata que faz desaparecer seus trânsitos, matérias e peso.

Orientada por um duplo registro de reflexão teórica e prática artística. A ficção foi um mote para tocar o real, como processo metodológico de pensar, conhecer e infiltrar lugares blindados e institucionais, trazendo pela via da imagem e da escrita, os fragmentos da invisibilidade da história atual. Assim, a busca de um ponto de vista, um tempo e uma distância onde se vê na espreita, ou ainda, no ponto frouxo do sonho, a possibilidade de algum despertar.

Fazia 40 graus naquele ano quando disparavam as filmagens rumo às terras remotas. Ao longo de todo ano, o desconforto do vapor quente e da poeira constante eram a notícia cotidiana nos jornais e nas redes sociais. Ainda ressoavam algumas poucas e dispersas notícias sobre as novas minas, afinal, agora a concessão para mineração crescia fortemente, depois do boom no preço da commodity que se iniciou no ano de $2009^{1}$, e toda a política econômica passou a ser pautada na venda desse subsolo. Após este ano, as caminhonetes Hilux, entre outros carros de desenho robusto e barulhentos, começavam a chegar e engarrafar o trânsito de muitas cidades mineiras. Com a concessão mais fácil e a tecnologia disponível trouxeram a transformação permanente da natureza desses lugares.

Em busca dessas terras remotas e das zonas de ressaca produzidas, viajei cerca de três anos em territórios e naturezas inóspitas, numa busca incessante e obstinada pela montanha que enviamos dia a dia em cerca de 35 navios de 450 mil toneladas. Vi o campo minado do subsolo que avança

\footnotetext{
${ }^{1}$ A palavra inglesa "commodity" significa simplesmente mercadoria. Mas no mercado o termo se refere a produto básico, em estado bruto ou com baixo grau de transformação. Disponível em: < https://www.nexojornal.com.br/explicado/2016/03/31/ As-commodities-e-seu-impacto-na-economia-do-Brasil>.
} 
e amplifica silenciosamente as escavações. Recoberta de restos, a superfície solta os vestígios da disputa e da racionalidade; covas, cavas, lama, poeira, paisagens monótonas e restos humanos. $\mathrm{O}$ estado de arruinamento e as ruínas produzidas dizem da incapacidade de leitura e da proximidade com as leis naturais, no ponto em que o espaço da catástrofe se funda.

As escavações seguem a transportar e deslocar não só matérias, mas também energias, eixos de gravidade e forças ainda não descobertas, ao mesmo tempo em que fazem surgir as zonas de ressaca como sobras desses movimentos da economia. Essas zonas estão entre a instabilidade e a latência de um estado que se estabelece na agitação da ressaca e na monotonia do coma, em um movimento de refluxo. ${ }^{2}$

Parece que até a noite anterior ao fim das viagens, naveguei em direção ao que Maurice Blanchot em Um livro por vir conta sobre o Canto das Sereias que se destinava "a navegadores, homens do risco e do movimento ousado, e era também ele uma navegação: era uma distância, e o que revelava era a possibilidade de percorrer essa distância, de fazer, do canto, o movimento em direção ao canto" (BLANCHOT, 2005, p. 4). Foi num movimento em direção ao canto que a tessitura dos textos e da produção visual dos filmes foi construída. Se o canto das sereias era em certa medida um risco àquele que ouvia, era também parte da distância e ao mesmo tempo uma navegação. Aqui, o movimento de encontro com um mundo em "desmoronamento" um lugar das potências imprevisíveis do porvir.

A ressaca das noites e da poeira se acumulou. O navio, as cavas e a jornada ficcional que havia criado para os filmes paulatinamente se entranharam em meu corpo. Havia me habituado com a terra vermelha e a poeira constante da terra solta da mineração. No entanto, naquela noite, depois que já havia se passado 15 dias após o fim das filmagens nas minas, a memória começava a avisar onde tinha chegado tudo o que havia visto. Os sons, que invadem nossos ouvidos passivamente, chegaram antes da imagem. Naquela noite, dentro da escuridão do sonho, escutei tudo batendo, era o barulho de ferragens gigantes e velhas. Mais ao longe, persistiam os rangidos dos guindastes, escavadeiras e explosões. $\mathrm{O}$ ronco dos desmoronamentos permanecia sem que eu pudesse ver. Sabia que era uma cava. Tudo permanecia ainda na escuridão. Um grande estouro, uma pausa, e de repente, como mastigadoras de pedras, as escavadeiras avançavam, aproximando o som do lugar onde eu estava. Os clarões além da mata eram o ponto de referência. De lá vinha o som, com rajadas

\footnotetext{
${ }^{2}$ Do latim Re, atrás e Fluere, fluir. Refluxo é, pois, fluir para trás.
} 
largas. Naquele ponto, o barulho da terra era ouvido das mais diversas formas, até que de repente, uma nuvem de poeira que embaçava a vista aparecia. Através dela já se via a cor bege-avermelhada.

Agora o som tinha chegado às memórias mais remotas. As escavadeiras haviam entranhado e chegado bem perto daquele lugar protegido da memória - a casa em ruínas do sítio da infância, de nome Córrego Fundo.

No sonho, a memória da casa em meio à mata se desfazia na terra vermelha. A última visada de lá continuava como o lugar mais distante que havia visto, escondida em meio à mata. Completamente ilhada, no sonho, só restava uma pequena porção de mata ao redor, as poucas árvores seguravam a grande trinca no piso prestes a cair na cava que se formava do lado de fora. Do lado de dentro da casa já sem teto, pela pequena janela, via as escavadeiras enfileiradas e caminhões para todos os lados. Trabalhavam dia e noite em direção à casa. Pouco a pouco, a imensa cava de terra vermelha brilhante se aproximava. O som das escavadeiras rugia cada vez mais perto. Até que a última luz dos faróis se foi, quando, bruscamente, a escavadeira parou.

Na minha casa da infância, durante anos, havia uma escavadeira ao pé de um grande buraco, encalhada e congelada no tempo, sob uma crosta de poeira, cheirava a ferro. Parada, servia de pausa e reinvenção de uso, onde nós desbravávamos e víamos todos os seres e invenções radicais de uso, ao lado de uma cova de cerca de 10 metros. Aquele canto da cidade era daqueles lugares esquecidos, às margens do urbano - lugar onde o capim avança, onde a natureza faz fronteira. Ali a escavadeira era a imagem ideal de uma pausa oportuna frente à iminência do acidente, de onde não se leva nem mesmo os objetos pessoais quando se avista um desastre. Ali restava o uniforme bege deixado sobre o volante que fundia-se com a poeira do interior da escavadeira.

A escavadeira no pé do morro da casa da infância retornava como o fóssil metálico deixado pelo não pagamento do empreiteiro e pela crise econômica, ressurgia naquela noite rugindo do lado de fora do sítio Córrego Fundo. O som dos estrondos e a escavadeira rasgando a terra é o que formavam a imagem naquele sonho. $\mathrm{O}$ som vibrava até tremer o chão da casa. As memórias, imagens que vi, escrevi e produzi ao longo dos filmes 3

\footnotetext{
${ }^{3}$ Subsolos é um média-metragem gravado em áreas de cavas de mineração e de bairros em processo de desapropriação para expansão de minas. Navios de Terra é um longametragem gravado na China Brasil e alto mar.
} 
retornaram caoticamente e em outros estados, no que Walter Benjamim chamou de um estado de sonho, o intermediário entre o sonho e o acordado.

Acordei tempestuosamente, ainda sobre o assombro das escavadeiras e caminhões enfileirados formando um estado de guerra, o tremor da terra implodida que ainda reverberava, mas, sobretudo, o assombro de onde as escavações tinham chegado, naquele lugar ainda protegido pela mata e pelas lembranças. Eram 6 da manhã quando consegui dormir por mais uma hora até o horário do café. E no sono entre-acordado sonhei por mais uma hora com a terra vermelha, repetidamente, como caísse num grande buraco sem fundo. As memórias me assombravam e o cansaço misturava memória com o que tinha visto ao longo das viagens e imaginado para o filme que estava gravando.

Sob a penumbra onírica, entre o dia e os pensamentos noturnos, a trinca, a infiltração da terra dentro daquela casa de 25 anos atrás - a rachadura não exatamente como a ideia clara do que poderia ser, mas a percepção do risco. O desastre "ele é desde sempre passado e, entretanto, estamos na beira ou sob ameaça; todas as formulações que implicariam o porvir se o desastre não fosse o que não chega, o que barrou toda chegada".(BLANCHOT, 1980, p.7). ${ }^{4}$ A iminência de um deslizamento rondava os sonhos.

Ao acordar, por um minuto pensei em contar ao Gustavo durante o café, mas logo lembrei que minha avó dizia que nenhum sonho deveria ser contado em jejum. Estava ali, presa na mesma casa onde minha avó havia dito que o sonho não poderia ser narrado antes do café. Esse sonho-imagem persistiu por alguns dias, até que me lembrei do texto Sala de desjejum de Benjamin no qual diz que "O homem acordado, nesse estado, permanece ainda, de fato, no círculo de sortilégio do sonho. [...] enquanto nas camadas mais profundas, mesmo durante o asseio matinal, a cinzenta penumbra onírica persiste e até se firma, na solidão da primeira hora que se desperta." (BENJAMIN, 1995, p.12). Assim, "quem está em jejum fala do sonho como se falasse de dentro do sono." Eu estava entre-acordada, entre o mundo diurno e noturno que forma o sono, num limiar ou uma zona de passagem. Talvez, nessa zona cinzenta onde

\footnotetext{
4 "Nous sommes au bord du désastre sans que nous puissions le situer dans l'avenir : il est plutôt toujours déjà passé, et pourtant nous sommes au bord ou sous la menace, toutes formulations qui impliqueraient l'avenir si le désastre n'était ce qui ne vient pas, ce qui a arrêté toute venue". (BLANCHOT, 1980, p. 9, tradução nossa).
} 
repousam as imagens, o despertar daquilo que nos acerta violentamente, ou, por melhor dizer, campo frouxo do substrato material que atravessa o corpo para além do pensamento. Afinal, como nos diz Benjamin, "Nós nos tornamos muito pobres em experiências de limiares. O 'adormecer' talvez é a única que nos restou." (BENJAMIN, 1995, p.12).

Deleuze, em Crítica e Clínica, nos diz que Lewis Carrol começa um combate que é das profundezas: "caixas são pequenas demais para os conteúdos, comidas são tóxicas ou venenosas, tripas se alongam e monstros nos tragam." (DELEUZE, 2006, p.31). E ainda nos diz que Alice no país das maravilhas era para intitular-se inicialmente "As aventuras subterrâneas de Alice". O título não permanece porque Alice conquista progressivamente a superfície e inicia um trabalho de deslizamento; "não que a superfície tenha menos não-senso que a profundidade, mas não é o mesmo não-senso, o da superfície é a "Cintilância" (...)" (DELEUZE, 2006, p. 31). Para Deleuze, essa diversidade de não-sensos dá conta do universo, na medida que a profundidade e a superfície são jogadas e misturadas.

O sonho é um estado de vigília e um oráculo probabilístico afirma Sidarta Ribeiro. ${ }^{5}$ Para o cientista, existe um paralelo entre o jogo e o sonho, porque simulamos o real enquanto dormimos. Talvez como forma de sobrevivência, experimentamos no adormecer as probabilidades. Sobretudo, repousa no sonho o instante impensado, o furo, aquilo que vaza o vivido, pode estar entre o passado e o futuro, entre a memória e a vidência. Sob uma perspectiva freudiana, Sidarta nos diz que o sonho são os restos do diurno.

De modo que estava no intervalo entre o sono e a imagem que se fixa quando acordamos - o estado de vigília, a espreita. Assim, estive à espreita ao longo da feitura dos filmes, na tentativa da captura do limiar, da fissura, do esgotamento. Benjamin, em Passagens, diz que "a história se decompõe em imagens, não em histórias.” (BENJAMIN, 2006, p. 518). Desse modo, estava diante de uma imagem que, no entanto, era uma imagem que começava cega na escuridão. Uma escuridão com os sons

\footnotetext{
${ }^{5}$ Sidarta Ribeiro é doutor em comportamento animal pela Universidade Rockefeller, com pós-doutorado em neurofisiologia pela Universidade Duke. Atualmente, é professor titular de neurociências e diretor do Instituto do Cérebro da UFRN. Trabalha atualmente nos seguintes temas: sono, sonho e memória; plasticidade neuronal; comunicação vocal; competência simbólica em animais não-humanos e neuroeducação. Disponível em: $<$ https://www.youtube.com/watch?v=S0p47aI4MzA $>$.
} 
e as vibrações das escavadeiras. Mas aqueles sons não eram novidade, já faziam parte da minha memória. Eu gostava de ouvi-los, como uma espécie de narrativa sem imagens, ou mesmo uma memória já vista pelas distopias inventadas pelo cinema.

Dos diversos modos de perceber, o som é aquele que marca a curva, reverbera até encontrar a barreira e percorre a textura e a matéria, vibra e ecoa até se perder na ação ou no movimento recém-acontecido. O som é o contato e o movimento entre as coisas no espaço, ele dá a profundidade e compõe o tempo das coisas.

Naquele ponto, o peso do minério, as constantes sirenes dentro de galpões gigantescos, entre sons agudos e longos com algumas interrupções de explosões davam a profundidade daquele espaço. Os sons formavam imagens do trabalho constante das máquinas e do corte das montanhas, alcançavam de alguma forma o deslocamento e o peso da matéria.

O som é aquilo que não se pode impedir. Se estamos diante de um filme ou acontecimento, podemos fechar os olhos, mas ele continua como formação daquilo que se passa. Há um incomum encontro entre o som e o sonho, afinal os sonhos parecem inaudíveis, mas funcionam como sismos autônomos aos excessos do que vemos. Estão no ponto frouxo, na possibilidade de algum despertar.

Como apontado por Adorno, "A intenção de Benjamin era desistir de toda interpretação manifesta e deixar o sentido aflorar tão somente pelo choque da montagem do material. A filosofia deveria não só subsumir o surrealismo, ela deveria tornar-se surrealista." (ADORNO, 1997, p. 217). Afinal, no sonho repousam as imagens que escapam ou que persistem, trazendo a derradeira possibilidade da urgência do despertar.

Entre todas as imagens capturadas e vistas ao longo dos anos, as escavadeiras persistiam. A escavadeira ao pé do grande buraco encalhada e congelada no tempo, sob uma crosta de poeira - era a imagem-fantasma que cheirava a ferro, e que subitamente retomava para um processo de retiradas. Aquela sempre presente em lugares esquecidos, ali, a escavadeira segue como a imagem ideal à iminência do acidente, do desastre que ronda o quintal.

Quando acontece, a catástrofe devora o mundo com resíduos, sobras e detritos - escombros. A matéria do tempo solta de uma só vez, desmoronada. A ideia do arqueólogo ou escavador perde então um pouco o sentido, afinal, das terras escavadas e dos escombros, tudo está sob a superfície. Inúmeros fragmentos diante de uma história complexa do mundo. No entanto, ainda pode ser o fragmento cintilante, 
a correspondência macrocósmica, "imagens que, desprendidas de todas as conexões mais primitivas, ficam como preciosidades nos sóbrios aposentos de nosso entendimento tardio, igual a torsos na galeria do colecionador". (BENJAMIN, 1987, p. 239). Então, talvez seja pelos fragmentos e cacos que a montagem e a desmontagem formulem uma história possível. "É por isso que a montagem decorre fundamentalmente desse saber das sobrevivências e dos sintomas, dos quais Aby Warburg afirmava que se parece com algo como uma "história de fantasmas para gente grande" (DIDI-HUBERMAN apud WARBURG, 2002, p. 103).



Foto: SHIMA

${ }^{6}$ A. Warburg. "Mnemosine" Grundbegriffe, II (1928-1929). Londres: Arquivo do Instituto Warburg, III, 102-4, p. 3. Cf. DIDI-HUBERMAN, 2002. 


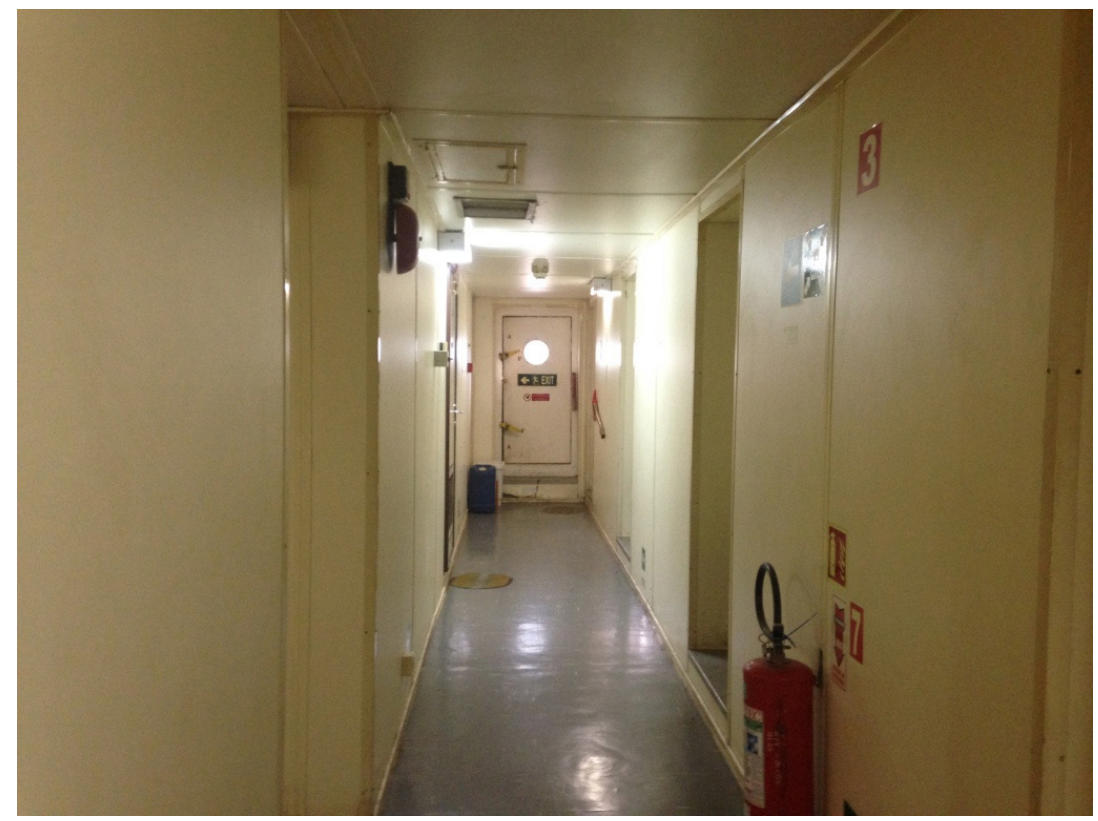

Foto: Simone Cortezão

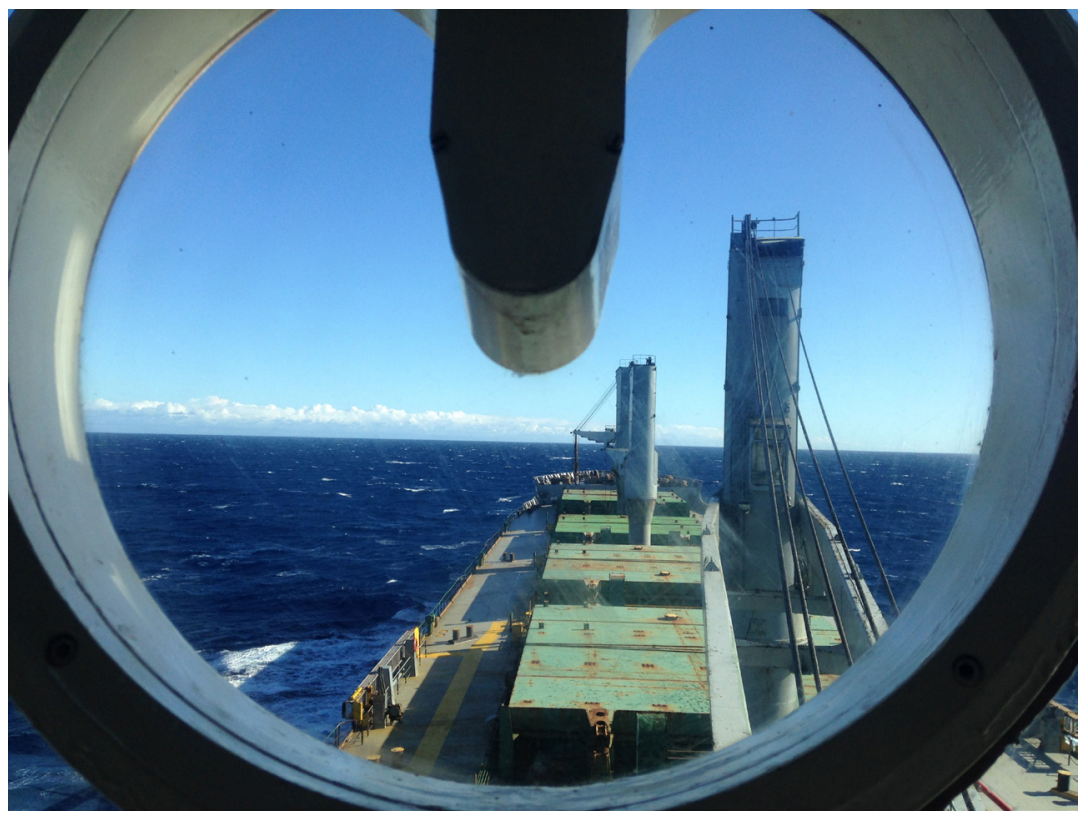

Foto: Simone Cortezão 
Foto: Simone Cortezão

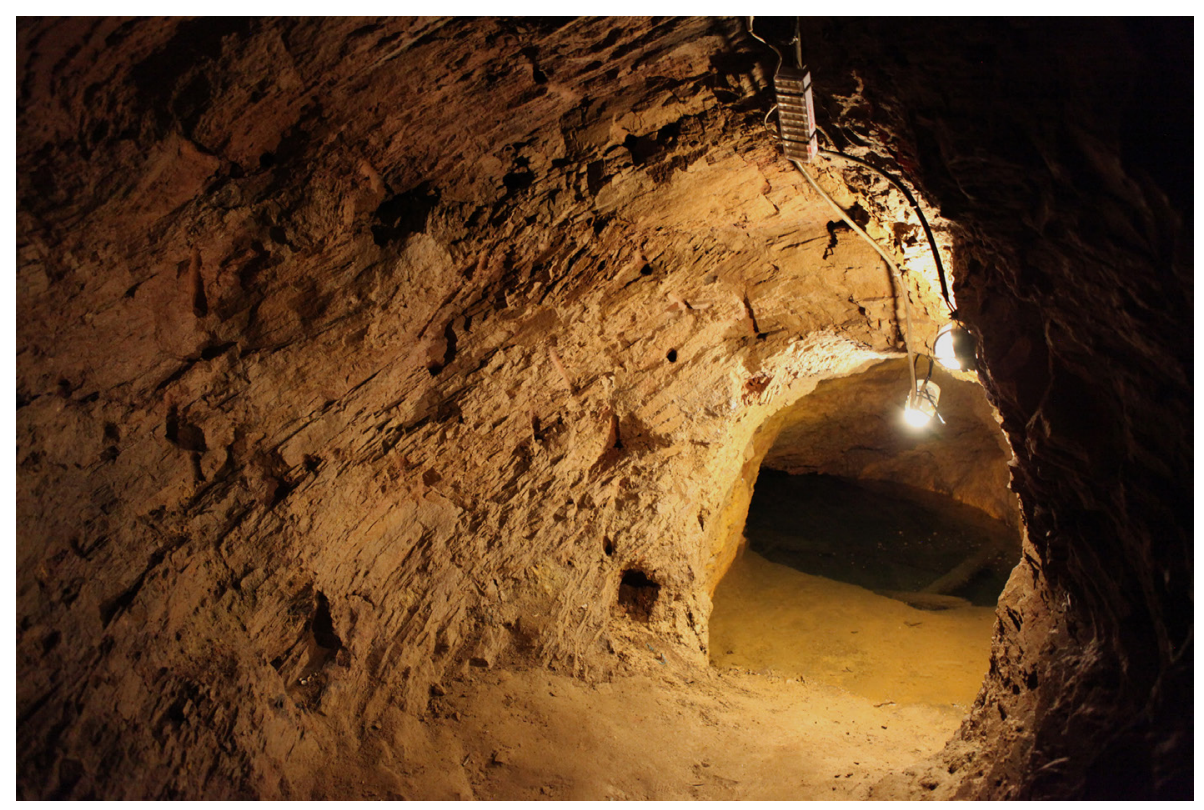

Foto: Simone Cortezão 


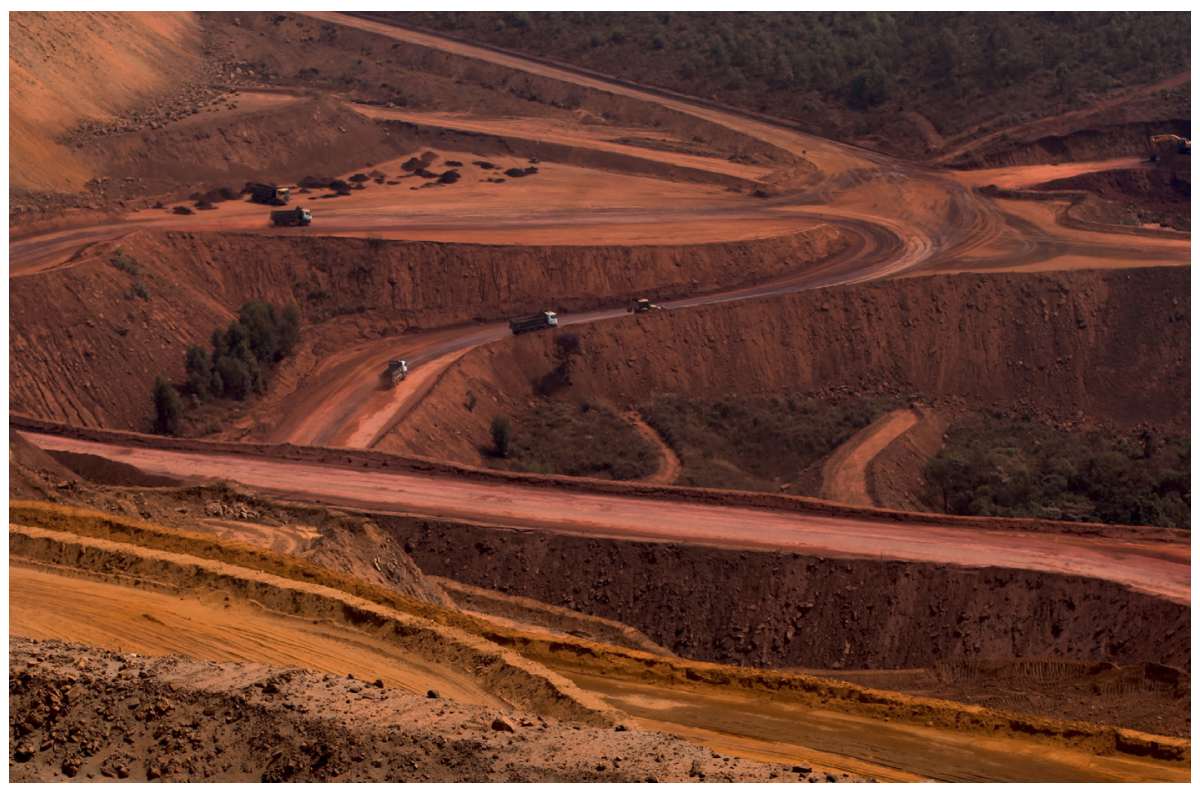

Foto: Simone Cortezão



Foto: Simone Cortezão 


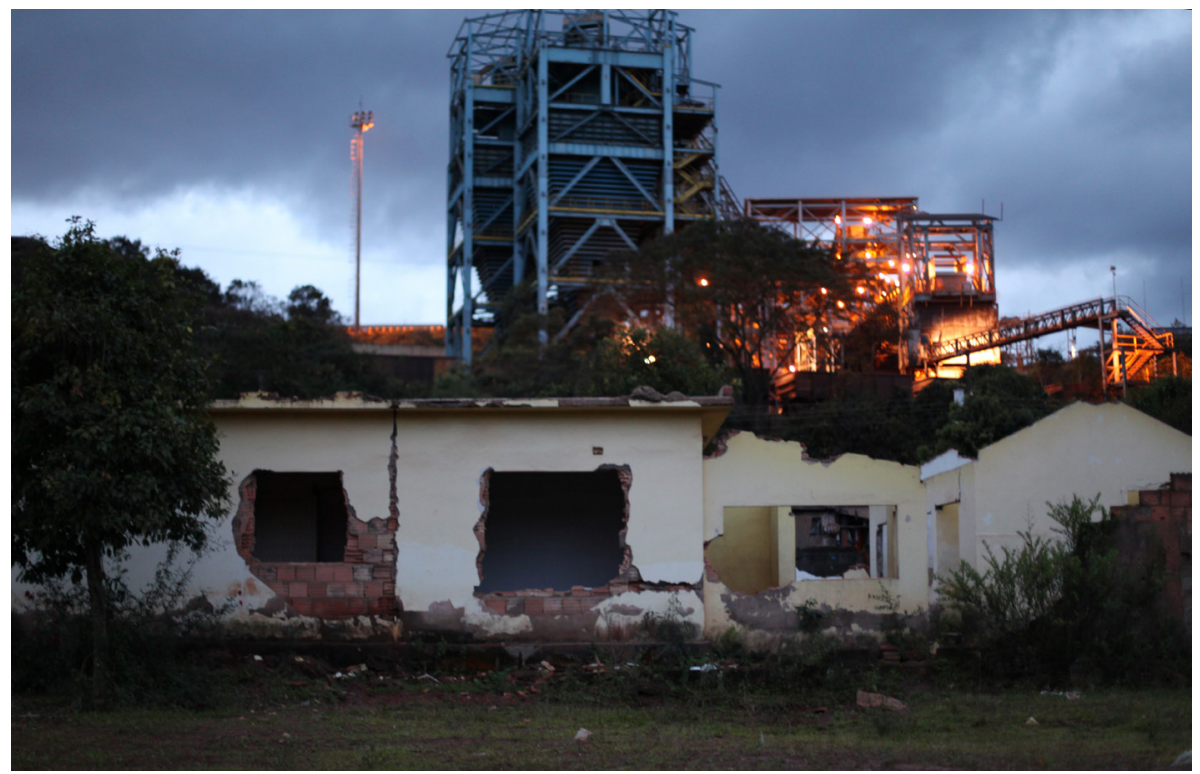

Foto: Simone Cortezão

\section{Referências}

ADORNO, Theodor. Caracterização de Walter Benjamin. Trad. Flávio Kothe. In: . Prismas: crítica cultural e sociedade. São Paulo: Ática, 1997.

BENJAMIN, Walter. Rua de mão única. São Paulo: Editora Brasiliense, 1995. v.2.

BENJAMIN, Walter. Arquivo N. In: . Passagens. São Paulo: Imprensa Oficial do Estado de SP; Belo Horizonte: Ed. UFMG, 2006.

BLANCHOT, Maurice. A conversa infinita 3: ausência de livro. Trad. João Moura Jr. São Paulo: Escuta, 2010.

BLANCHOT, Maurice. O livro porvir. Tradução de Leyla PerroneMoisés. São Paulo: Martins Fontes, 2005.

BLANCHOT, Maurice. L'écriture du désastre. Paris: Gallimard, 1980. 
BRETAS, Aléxia. A constelação do sonho em Walter Benjamin. São Paulo: Humanitas; Fapesp, 2008.

DELEUZE, Gilles. A imagem-tempo. São Paulo: Brasiliense, 1990.

DELEUZE, Gilles. Crítica e Clínica. São Paulo: Ed. 34, 2006.

DIDI-HUBERMAN, Georges. O que vemos, o que nos olha. São Paulo: Ed. 34, 1998

DIDI-HUBERMAN, Georges. L'Image survivante. Histoire de l'art et temps des fantômes selon Aby Warburg. Paris: Minuit, 2002. 